\title{
Accuracy Evaluation of the Semi-automatic 3D modelling for Historical Building Information Models
}

\section{Antón, Daniel}

Departamento de Expresión Gráfica e Ingeniería en la Edificación Escuela Técnica Superior de Ingeniería de Edificación, Universidad de Sevilla 4A Reina Mercedes Avenue, Seville, 41012, Spain.

Telephone: +34644351215

Fax: +34 954556628

danton@us.es

\section{Medjdoub, Benachir}

The Creative and Virtual Technologies Research Laboratory

School of Architecture, Design and the Built Environment

Nottingham Trent University

50 Shakespeare Street, Nottingham, NG1 4FQ, United Kingdom

Telephone: +44 (0)115848 2313

benachir.medjdoub@ntu.ac.uk

\section{Shrahily, Raid}

The Creative and Virtual Technologies Research Laboratory

School of Architecture, Design and the Built Environment

Nottingham Trent University

50 Shakespeare Street, Nottingham, NG1 4FQ, United Kingdom

Telephone: +44 (0)115848 2313

raid.shrahily2012@my.ntu.ac.uk

\section{Moyano, Juan José}

Departamento de Expresión Gráfica e Ingeniería en la Edificación

Escuela Técnica Superior de Ingeniería de Edificación, Universidad de Sevilla 4A Reina Mercedes Avenue, Seville, 41012, Spain.

Telephone: +34954556677

Fax: +34 954556628

imoyano@us.es 


\section{Abstract}

It is stated that 3D recording and modelling of heritage buildings entails accurate building models (as-built). However, this paper presents an analysis of the 3D modelling accuracy for the creation of historical building information models (HBIM), considering the complexity and the deformations of historical buildings, using point cloud data and BIM tools. The 3D modelling processes analysed are based on a three-stage semi-automatic approach leading to the generation of HBIM, including manual and automatic processes. The three stages consist of: (a) optical and terrestrial laser scanning; (b) meshing processes; and finally (c) 3D solid modelling to be assembled into HBIM. Next, this approach analysed the mesh deformations generated automatically in comparison to the initial point cloud data. The deformations and the accuracy evaluation have been undertaken using different commercial software. Finally, our modelling approach shows that it can improve the accuracy of the 3D models achieved using existing BIM technologies.

\section{Keywords:}

Point cloud data; Modelling accuracy; Digital historical reconstitution; Architectural Heritage; Historical Building Information Models; 3D solid object; Terrestrial Laser Scanning; Optical Scanning.

\section{Introduction}

Building Information Modelling (BIM) for heritage is a fast-developing field in term of research and professional practice. 3D documentation of historical buildings and sites is a need nowadays for heritage conservation and its management (Remondino and Rizzi, 2010). The reliable 3D virtual reconstruction of architectural heritage is the logic step towards the achievement of as-built models by implementing the historical assets as a BIM model for 
conservation and management purposes. In this paper, we will focus on 3D scanning as a recording technique. To develop a reliable HBIM model, one of the challenges is to convert the point cloud data obtained from the 3D scanning into a three-dimensional information model as accurate as possible. Notwithstanding, certain drawbacks arise throughout this process, especially those concerning hardware and software. The files containing point clouds are massive because of the density of points and the dimensions of the point clouds themselves. As a result, the meshes created from these point sets entail large file sizes that must be managed using the available computer systems, which often show some computational limitations. For its part, software should experience further development in efficiency, since the current excessive time spent on processing is to be improved while visualising and performing operations with $3 \mathrm{D}$ objects.

Currently, there are great efforts in the automation of the modelling of heritage buildings from the point clouds. The implementation of this so-called "Scan-to-BIM" is rather recent. Its development especially consists of creating algorithms to generate building surfaces and boundaries from point clouds, following procedural rules and constraints to extract features of different parts in the buildings and create parametric objects. Nevertheless, apart from implying a rough approximation to the geometry of the historical buildings, if these complex automatic algorithms are not integrated in commercial software, they may not be reachable at standard user level.

As mentioned above, this paper deals with the important problem of transforming 3D point cloud data to an accurate Historical Building Information Model (Murphy et al., 2009; Nieto et al., 2016). To this end, it will assess the suitability and accuracy of existing methods and technologies for their use in the creation of these heritage models, for which a semiautomatic procedure is proposed. It has to be noted that each historical building is unique. Moreover, its components can also be significantly different, not being part of standardised BIM libraries. Therefore, following that semi-automatic procedure, and using equipment and affordable hardware and software, building components will be individually extracted from 
point cloud data according to the users' heuristic knowledge, since they can easily identify the extent of a building component and its relation in space with adjacent elements. Subsequently, being accurately meshed by fitting their actual geometry, and finally converted into 3D solids, these components will be assembled for the digital historical reconstitution of the buildings in HBIM models.

This paper also sheds light on the scientific literature as regards the virtual documenting of architectural and cultural heritage, and especially the use of Terrestrial Laser Scanning (hereinafter TLS) and its implementation in BIM software. Subsequently, the methodology explains the process to achieve 3D solid objects from TLS and Optical Scanning (OS) point clouds corresponding to the building components studied. To this end, the suitability of diverse 3D modelling software for the aim of this research is analysed. In addition, the implementation of building components in HBIM is developed, using as an example a singular historical building in Seville, Spain. Finally, the discussion of results and conclusions take place.

\section{Background}

The adoption of BIM in the AEC (Architecture, Engineering and Construction) industry is developing rapidly, however its implementation in facility management is slower, generating a need that the latest research approaches are beginning to satisfy (Volk et al., 2014). Considering that BIM implementation concern the building whole life-cycle, BIM becomes an interesting option to achieve efficiency in natural resources, costs and time (Volk et al., 2014). In the case of heritage buildings, although there is a real need to maintain, restore and manage the historical assets, BIM has not been implemented to its full potential, albeit in recent years this situation is being reversed (Logothetis et al., 2015; Logothetis and Stylianidis, 2016). 
Murphy et al. (2009) proposed a new information model (2D drawings and virtual layout) of historical structures from information obtained from laser scanning and digital images, including data related to the construction methods used. This new information model including historical information has been named the Historical Building Information Model methodology (Oreni, 2013; Hichri et al., 2013; Simeone et al., 2014; Nieto et al., 2014; Brumana et al., 2014; Barazzeti et al., 2015a; Chiabrando et al., 2016), an application of BIM to architectural heritage, which Murphy et al. (2013) defined as a novel prototype library of parametric objects. Following the work of Murphy, Nieto et al. (2016) underlined the importance of the interoperability of the information handled by the various disciplines involved in the process of conservation and patrimonial retrofitting.

The virtual reconstitution of heritage assets is the logical step towards the implementation of BIM for the generation of as-built models (Tang et al., 2010, Hichri et al., 2013, Saygi and Remondino, 2013). Therefore, in order to avoid manual 3D modelling of elements, this virtual reconstitution needs to obtain an accurate HBIM model from 3D scanning data (Logothetis et al., 2015). However, it may be desirable to model elements depending on the needs of the project. For example, Boeykens et al. (2012) undertook the virtual reconstruction of a synagogue destroyed during the war by using BIM, which requires non-standardised elements and therefore not available in BIM software libraries. In this sense, Baik et al. (2014) proposed libraries of architectural elements created using laser scanning and imaging. These libraries have been used in different HBIM projects while reducing modelling time. Other authors, such as Nabil and Saleh (2014), dealt with the 3D reconstitution of museum artefacts using the Structure-From-Motion (SFM) photogrammetric technique, which is a low cost and easy-to-use option for 3D digitisation.

For its part, TLS has been used successfully in detecting physical alterations in building structures during the construction and maintenance process: El-Hakim et al. (2004) 3D reconstructed large-scale heritage sites using image-based modelling and laser scanning; Barber et al. (2006) examined the application of TLS in architectural conservation; Olsen et 
al. (2009) studied damage detection and volumetric change; Armesto-González et al. (2010) combined TLS with digital image processing to study damages in stone materials of historical buildings; Guarnieri et al. (2013) used TLS, total station, and photogrammetry for stability control monitoring with finite element model (FEM) analysis applied to an historical building, and also disclosed the difficulties of the use of the scanning technique; Pesci et al. (2013) estimated the error in TLS measurements to correctly interpret deformation traces in buildings after earthquakes; Chellini et al. (2014) also used TLS and FEM to evaluate the seismic vulnerability; Kim et al. (2015) undertook quality control using localising and quantifying concrete spalling defects; Lezzerini et al. (2016) mapped the façade stonework of a church in Pisa, Italy, using computer-aided design (CAD) and geographical information system (GIS) software with laser-scanning data and high-resolution images; or Mukupa et al. (2016), who proposed a three-stage processing model for structural deformation analysis, based on the literature review regarding the use of TLS in the detection of structural changes and deformation monitoring.

Despite the widespread use of TLS in three-dimensional capture of existing heritage buildings, this technique is not used to obtain an accurate model of information from laser scanning. On the contrary, according to Xiong et al. (2013), in the field of engineering, surface models of mechanical parts have been converted into volumetric models by reverse engineering.

In the field of 3D modelling applied to existing historical buildings for BIM platforms, it is stated that the usage of data collected using 3D scanning techniques entails the achievement of real (as-built) building models, which is performed by point cloud acquisition, segmentation, and element recognition (Tang et al., 2010; Huber et al., 2011; Xiong et al., 2013; Murphy et al., 2013; Hichri et al., 2013; Thomson and Boehm, 2015; Chiabrando et al., 2016, Baik et al., 2017). Pu and Vosselman (2009) did not use the term Scan-to-BIM expressly, perhaps because the concept of this automation was in its early stages. Their work consisted of the automatic reconstruction of façade openings and elements from 
terrestrial laser scanning point cloud data. One year later, Hajian and Becerik-Gerber (2010) raised the point cloud inaccuracies of the 3D model inserted in BIM. Zeibak-Shini et al. (2012) developed a method to generate an information model of the deformed structures of existing buildings in case of earthquakes using laser scanning. After these initial works, several publications deal with the automation of the point cloud data (Jung et al., 2014; Previtali et al., 2014; Zhang and Zakhor 2014; Thomson and Boehm 2015), and more recently appeared an extensive state of the art of BIM applied to the historical building by Dore and Murphy (2017). Special attention can be given to Thomson and Boehm (2015), who used algorithms for the reconstruction of geometry from point clouds and their classification in Industry Foundation Classes (IFC) models. Hong et al. (2015) proposed a semi-automatic method for the creation of BIM in interiors, generating a 3D wireframe model combined with clutter data to achieve an as-built model in BIM. Jung et al. (2014) addressed point cloud segmentation and the elimination of its background noise, thus tracking the boundaries of figure contours. The segmentation was performed through the RANSAC algorithm (RANdom SAmple Consensus). The characteristics of planes and points were incorporated into BIM software, using them as references for the construction of the parametric elements. Zhang and Zakhor (2014) proposed an algorithm to automatically identify sectors of windows on exterior façades through the point cloud. Their research was limited to obtaining the results of segmentation rather than ease the processing of BIM objects.

With all the above, one of the great advantages of the Scan-to-BIM automation procedures is saving time and human resources in the handling and management from the point cloud to the construction of the parametric objects of the model. However, Thomson and Boehm (2015) state that one of the issues to solve is the difficulty of representing irregular geometries in BIM platforms. In this sense, for example, there are deformations in historic buildings, as well as complex singular elements in churches and cathedrals. Bassier et al. (2016) modelled a heritage timber roof structure from TLS point cloud data, performing 
manual segmentation, but did not specify the extent the meshes fit the point cloud to assess their accuracy. Having modelled the ensemble, they evaluated the structural behaviour of the 3D model. This shows the relevance and utility of methodologies that model heritage buildings more realistically.

Modelling elements from contours generated automatically from the point clouds by a series of algorithms, transfer the original, irregular, and detailed forms to excessively simplified shapes in some cases. The buildings can also be modelled in BIM by taking the point cloud as a reference, but the result is a theoretical model devoid of all the detailed deformations and thus of the real condition of the building. Moreover, even if this theoretical model can be deformed later, it is still a purely manual and prone to error task. For example, Fai et al. (2011) and Mill et al. (2013) integrated the point cloud data of the TLS - assisted by other techniques - into BIM software to create building models. For their part, Dore and Murphy (2013) modelled buildings semi-automatically from these point clouds using the GDL (Geometric Description Language) programming language of ArchiCAD software. On other occasions, certain architectural elements are implemented in information models, but not as a basis for the model itself, but as a complement to its visualisation (Nieto et al., 2016). Other research (Altuntas, 2015, Altuntas et al., 2016) has integrated point clouds from the image, either by time-of-flight (TOF) cameras or by photogrammetry, in the point clouds obtained by TLS applied to complex geometries in architectural heritage, but its purpose is usually the visualisation. (Oreni et al., 2014), Dore et al. (2015) approximated the geometry of their model by segmenting and sectioning the point clouds at different heights, creating surfaces that constitute enclosures with a certain degree of deformation. As a result, the generation of multiple sections could entail the omission of the graphical information -deformations in this case- that actually exists between them.

In conclusion, there is a clear need to integrate accurate geometry into information models (HBIM). Collecting this kind of geometrical data is essential for the management of the 
architectural heritage, whether for its restoration, maintenance or the dissemination of the richness that these historical assets entail.

\section{Methodology}

As stated by Hichri et al. (2013), the problem of achieving an 'as-built' model is solved by taking into account three fundamental steps: data acquisition, segmentation, and 3D modelling.

In this project, the geometrical data was acquired using two different 3D scanning techniques: terrestrial laser scanning (TLS) and optical scanning (OS). The equipment used for this purpose was a Leica ScanStation C10 3D Laser Scanner (Leica Geosystems, 2016b) and a handheld Artec MHT 3D Scanner, respectively. The resolution of the former scanner was configured to reach $5 \mathrm{~mm}$ resolution, whereas the latter works with $1 \mathrm{~mm}$. TLS was used to generate the global historical building model, containing those elements whose geometry - deformations - can be successfully recorded with lower resolution, namely walls, arches or column shafts. On the contrary, in the case of highly detailed building components, such as column capitals, door and window panels, the recording of their geometry was carried out using OS. This device can be also used to scan those elements that show characteristics or defects which should be recorded due to their impact on the model in terms of visualisation, classification or other uses. It is worth mentioning that the use of OS is limited to scanning specific, detailed building components, since its resolution causes the file size to increase. The aforementioned limitations in hardware and software make OS unable to record the geometry of the whole building. Figure 1 justifies the acquisition of OS data, which provides higher resolution that TLS for certain components.

$<$ SET FIGURE 1>

Figure 1. TLS and OS accuracy difference in a column capital. 
In order to obtain reliable point cloud data of the buildings and their elements, the survey must ensure certain features in the 3D data. The volume of the elements has to be well defined by carrying out a full scan surrounding these elements. In the case of an incomplete scan of a building component - some faces only - will result in insufficient number of surfaces to create a closed volume. In addition, the point cloud should be dense in order to produce an accurate mesh. We can define an accurate mesh as a triangulated mesh that fits the point cloud from which it gets its geometry after a meshing process.

As stated by Tang et al. (2010) the TLS point cloud has to be aligned in a common coordinate system; this is known as registration process. In the 3D laser scanning, three targets were located in the building to connect the readings of the device in each position. The scans overlapped so that they could be aligned using Leica Cyclone 9.1 (Leica Geosystems, 2016a), that also detects matching areas and creates cloud-to-cloud constraints automatically. Concerning other detailed structural components such as the column capitals, which were scanned using the OS, an alignment process with respect to TLS coordinate system must be undertaken. This OS mesh registration can be done after the components from TLS point cloud have been meshed to ease the identification of control points and edges. In order to guarantee the correct orientation of these components in the building, positional references must be recorded. Several control points for identification in the edges and vertexes of the arches are taken from the original OS meshes and also supported by photographs of the archwork, taken during the 3D survey. The orientation in the $Z$ axis was based on these references or control points. For its part, the horizontal alignment of the capitals was conducted considering their XY plane in the upper base of the capitals according to the impost of the arches. Once the data are acquired, a three-step procedure takes a place. Figure 2 illustrates this method:

\section{$<S E T$ FIGURE 2>}

Figure 2. Flowchart explaining the 'Point cloud — mesh - 3D solid object' process. 
It must be noted that this research proposes a semi-automatic procedure to achieve accurate HBIM models, comprising manual tasks and automatic processes. On the one hand, manual tasks are point cloud subdivision, brushing (if necessary), file conversion, implementation in $\mathrm{BIM}$, and OS solids alignment and orientation. On the other hand, automatic processes include OS data recording, meshing, hole filling, repair and invert/unify normals, simplification (if necessary), and NURBS conversion.

The first step in the methodology consists of importing the registered point cloud data into Leica Cyclone (in the case of the TLS) and then, based on heuristic knowledge, perform the point cloud subdivision into diverse building components in order to extract the desired sectors to study.

The second action consists of importing these extracted TLS point sets into Rhinoceros 5 (Robert McNeel \& Associates, 2014) (hereafter Rhino), so that the meshing process can be performed using the Mesh Flow plug-in (Mesh Reverse, 2016). Concerning the OS, the point cloud data is automatically meshed in Artec Studio 10 Professional (Artec 3D, 2015) (hereinafter Artec), which is the native software of the OS device used; the first step of point cloud subdivision is then omitted in this case. Subsequently, it is worth using the 'Repair' tool in Artec or the 'Check' command in Rhino in some stages of this procedure - especially when the meshes are imported into different software - in order to verify that the meshes display valid geometry. Non-multiple faces, duplicated faces, naked or non-connected edges, and incoherent normals are examples of errors in meshes. The normal vectors of the triangles must face outwards (Unity Technologies, 2016) with respect to the volume; otherwise the object surface is not coherent. To this end, these normals must be unified (Robert McNeel \& Associates, 2015) by running the UnifyMeshNormals command, thus inverting vectors aiming inwards. A hole filling process must be also undertaken so as to obtain watertight meshes to create volumes. This can be directly carried out in Rhino or using Artec, which additionally displays intuitive interface and tools to treat the mesh, namely 'eraser', 'smooth brush' and 'defeature brush' to eliminate or reduce triangles out of context. 
When facing large file sizes, the simplification of meshes is another option to consider. Its extent should be according to the details (geometry) and dimensions of the objects, inasmuch as a recognisable geometry must be guaranteed in the resulting simplified mesh. Id est, there should not be excessive information loss; otherwise the models would not be representative of the building components studied.

The third step is to use Rhino to convert the resulting closed meshes into closed NURBS (Non Uniform Rational Basis-Splines) polysurfaces, which become the 3D solid objects of the elements scanned (as seen in the right column capital in Figure 1). This last step is conducted for both TLS and OS data, running the MeshToNURB command. Although this is a modelling method which meets the aims of this research, there are other options to obtain 3D solid objects from the resulting meshes. These options include: 1) insert individual NURBS polysurfaces in AutoCAD Architecture 2015 (Autodesk, 2014) and run the SURFSCULPT command, which trims and combines a set of surfaces or meshes that completely enclose a volume to create a 3D solid; 2) import a watertight mesh in AutoCAD, convert it into a 'mass element' and then into a 3D solid object.

These NURBS polysurfaces achieved differ from those NURBS created by Murphy et al. (2013), who built 2D profiles from parts of elements using Boolean operations and then repetition to conform the elements; or those by Oreni et al. (2014), who generated surfaces that arise from a spatial deformation of a grid of square tiled surfaces (patch surfaces) in which the positions of the control points determine the deformation. Again, NURBS have been used by Barazzetti et al. (2015b) and Fregonese et al. (2017) to create the elements. Especially in the vaults, several sections were extracted from their point clouds by interpolation in order to obtain the 3D models. Although all these methods approximate the shape of complex building components, these methods are not within the scope of this paper. In addition, the 3D solid models here obtained are not mathematically modelled on the basis of quadric surfaces such as paraboloids or cylinders, but they come directly from closed meshes from the segmented and managed TLS point clouds, using NURBS as a way 
to become closed polysurfaces (solids). As illustrated in Figure 1, the surface of the solids is not regular. Their surface contains the deformations and peculiarities in the geometry of those elements of architectural heritage directly scanned using OS.

In order to verify the results of the modelling process, Boolean operations - addition/union, subtraction/difference and intersection - can be performed between these 3D solid objects and primitive $3 \mathrm{D}$ entities such as cubes or cylinders. When the latter subtract certain volume from the former, the result should be also solid instead of hollow (this would be the case of a closed mesh). Besides, these operations can be applicable to combine solid objects in order to create the desired building component.

Consecutively, the 3D solid objects are imported into BIM software applied to architectural heritage, by following the HBIM methodology. This is conducted piece by piece and according to the construction logic, reconstructing the original arrangement of the building components and the building itself. The import is solved considering the IFC open file format (buildingSMART International, 2017; ISO, 2013), due to its native compatibility with BIM software. In this way, for instance, the 3D solid objects of the column capitals could be converted into GSM parametric objects through GDL (Dore and Murphy, 2013), since ArchiCAD 20 (Graphisoft, 2016) (hereafter ArchiCAD) is the BIM software employed in this research. The parameters of those objects can be set, such as positional, physical, and structural properties; likewise visualisation can be customised according to the research or project needs.

\section{Software analysis and implementation}

In this section, the methodology above is implemented to show how the digital historical reconstitution of a historical building in HBIM can be performed. Prior to this, a comparison between the programs used for achieving the 3D meshes must be undertaken. 


\subsection{Comparative study: existing systems}

In this research, we have tested different software to compare their performance and suitability to convert point clouds from 3D scanning techniques to 3D meshes. In some cases, the meshing process did not produce suitable results. On the one hand, although this can be repaired afterwards, two different applications solved certain sectors of a mesh erroneously when the normals of some points aimed inwards, while in the rest of the points other normals targeted outwards (appropriate direction for volumes). In some cases, instead of meshing the point cloud accurately according to the original arrangement of the points, open source applications such as CloudCompare (Girardeau-Montaut, 2016) or MeshLab (Cignoni et al., 2008), executing the Surface Poisson Reconstruction command (Kazhdan and Hoppe, 2013), formed a bubble connecting the correct edges avoiding inverted normals or holes, which is not the desired result. The reason for this could be the lack of points in the scanner data due to inefficient surveys, or if a surface mesh - not a volume - is intended to be closed. On the other hand, another programme (SolidWorks by Dassault Systèmes and SolidWorks Corporation (2017)) created non-valid faces in the mesh, making it impossible to export the geometry in these sectors as valid 3D objects. Finally, another Rhino plug-in produced insufficient accuracy in the meshes. It was the case of MeshFromPoints (Figure 3), which did not adapt the resulting meshes (in green colour) to the point clouds (in yellow) as MeshFlow showed (in red).

\section{$<S E T$ FIGURE 3>}

Figure 3. Results from different meshing plug-ins in wireframe display mode.

This means a loss in relief, which is not appropriate for recording deformations and irregularities in the building components.

The difference in results using both plug-ins should be quantitatively specified. To this end, Table 1 briefly justifies the election of MeshFlow (1) against MeshFromPoints (2), being the 
former chosen as the reference mesh in the comparison. In this research, we use the standard deviation, given the fact that this statistical measure quantifies the dispersion of data set values, corresponding with the vertexes whose location has changed with regard to the original - or reference - mesh when performing the meshing process. The comparison (Girardeau-Montaut, 2015) was performed using CloudCompare v. 2.7.0 between the two sample meshes.

\section{$<$ SET TABLE 1>}

*This value accounts for the equality between the meshes compared.

Table 1. Mesh feature comparison between different meshing plug-ins.

As shown in Figure 3 and Table 1, in addition to increasing the surface of the meshes, MeshFromPoints reduces the amount of points and faces significantly.

As stated in the previous section, only the point clouds from the handheld 3D scanner are directly meshed in Artec. On the contrary, those geometries captured by the 3D laser scanner are generated by importing the original point clouds in Rhino. Therefore, it is worth displaying the deviation - error or lack of similarity - between the resulting meshes using the aforementioned software in different file formats. Also used in the comparison above, a portion of an irregular stone surface (see Figure 4) was selected to evaluate the accuracy of commercial software packages.

\section{$<$ SET FIGURE 4>}

Figure 4. Sample of irregular stone surface.

The geometry of the stone surface was captured using the Artec MHT 3D scanner; therefore, this mesh was considered as the reference of the comparison. On the contrary, the compared mesh is generated by importing the original point cloud from that mesh in Artec into Rhino. This means that both point clouds were the same in the comparison. The orientation of the point cloud was established in Artec prior to exporting this point set to 
Rhino, so that the two meshes had the same position for the comparison and alignment errors were then prevented. Table 2 shows the results of the comparison:

\section{$<S E T$ TABLE 2>}

*This value accounts for the equality between the meshes compared.

**Standard deviation applicable in case of Artec STL - Rhino STL.

Table 2. File formats and mesh feature comparison in the case of the stone surface.

High standard deviation values $(\sigma)$ represent practically identical compared mesh and reference mesh, since the most of the points between them maintain their position after the meshing process. On the contrary, reduced values of $\sigma$ between these sample meshes entail a considerable number of vertexes distant from those points of the reference mesh (see value zero of the intervals in Figure 5). The exception is the multiple case of $\sigma=0$, where the lack of deviation is due to the fact that all the vertexes in the compared mesh belong to the value zero; in this case, the empty distance intervals (i.e. containing no points) can be omitted.

The standard deviation value between the sample meshes using Artec and Rhino in PLY format is illustrated in Figure 5 as vertex disposition for distance intervals.

\section{$<S E T$ FIGURE 5>}

Figure 5. Stone surface: mesh deviation comparison graph.

As indicated in Figure 5, the major part of the points/vertexes are located in the area corresponding to the interval of distance equal to zero, since the distance between the vertexes of both meshes is null; this indicates where the two meshes are similar. In the graph, the arrangement of the rest of the points in the compared mesh depends on their distance from those in the reference mesh. This can be taken into consideration when analysing the comparison between the Artec PLY and Artec STL meshes (see Table 2). In this case, the extremely high standard deviation value of the Artec STL mesh is due to scarce, scattered points existing in the rest of intervals compared to the place where the 
distances are null (where the major part of the vertexes is placed). This evidences the great similarity between the two meshes of the comparison.

In addition, it is worth mentioning that an approximate symmetry between vertexes of both reference and compared mesh exists in the prior graph, as also occurs in Figure 7. Taking into account that Rhino was used to create the meshes from the point clouds obtained by 3D scanning techniques, it could be stated that this software balances the arrangement of the resulting faces (triangles) to achieve an approximate geometry.

The intersection or overlap between the reference mesh and the compared one is shown in Figure 6, which displays in $\mathrm{mm}$ the histogram in Figure 5 and translates it into model space, so that the deviation between meshes can be directly visualised using colour code.

\section{$<S E T$ FIGURE 6>}

Figure 6. Comparison histogram: deviation between Artec PLY and Rhino PLY meshes.

The aforementioned symmetry can also be noticed in Figure 6. The positive and negative values are arranged in accordance with the intervals in Figure 5. Those values are the faces or triangles belonging to the compared mesh above (green to red) or below (green to blue) the surface of the reference mesh. The intervals displayed in this histogram account for the arithmetic mean between those in Figure 5, since the latter figure contains more intervals and it is necessary to reduce their number.

The comparison is also carried out in the case of the column capitals of the Pavilion. One of the capitals in the western façade is selected for this analysis (Table 3):

\section{$<S E T$ TABLE 3>}

\footnotetext{
* This value accounts for the equality between the meshes compared.

**Standard deviation applicable in case Artec STL - Rhino STL.
}

Table 3. File formats and mesh feature comparison in the case of the column capital. 
Figure 7 displays the visual deviation between the new reference mesh (Artec PLY) and the compared one (Rhino PLY) in the case of the column capital.

$<S E T$ FIGURE 7>

Figure 7. Capital: mesh deviation comparison graph.

Both graphs are created at the same scale in order to compare the differences visually.

\subsection{Implementation: the Pavilion of Charles V}

This research is based on the analysis of a heritage building in Seville, Spain. Placed in the gardens of the Alcázar, this Renaissance-characterised building is called the Pavilion of Charles V. It is part of the monumental complex of the Alcázar, which was included in the World Heritage List of UNESCO (1987) because of its great cultural value. The Pavilion (Figure 8) shows signs of the course of time and deferred maintenance due to numerous pathologies present in structure, floor and wall tiling.

\section{$<$ SET FIGURE 8>}

Figure 8. Historical Building Information Model (HBIM) of the Pavilion of Charles V. Source: (Nieto et al., 2016).

Nieto et al. (2016) developed the HBIM of the Pavilion without investigating the accuracy of the model nor quantifying the deformations which could occur during the process. Undoubtedly, the main target of this research was not to achieve an as-built model, but to provide the professionals involved in the conservation and restoration process with information to support the management of the historical asset.

In contrast, this paper represents the real condition and thus the state of preservation of the Pavilion. To this end, the digital reconstitution focuses on the columns in the southern façade of this historical building, including their bases, shafts, capitals, arches and the beam above 
the ensemble. For this purpose, the methodology explained in section 3 is followed: the point clouds from TLS are meshed, then converted into 3D solid objects, and subsequently imported in HBIM as IFC files, which allow the professionals to access the full information model.

Figure 9 shows the result of the digital historical reconstitution by building components proposed in this paper.

\section{$<$ SET FIGURE 9>}

Figure 9. 3D reconstitution and HBIM. Arches and columns in the Pavilion of Charles V.

It is worth mentioning that, thanks to the registration of the TLS point cloud at the first stage, the original position of each extracted building component is already established when importing them as IFC files, since their origin is a common point set of the whole building.

\section{Discussion of results}

Prior to creating the HBIM model for the virtual reconstitution of architectural heritage, this paper addresses the important problem of mesh deformations, which occur during the process of transforming the point clouds to a mesh. The results of the comparison between meshes using different software show the following:

- Considering the STL file format for 3D models, the outcomes of this comparison (see Table 2 and Table 3) reveal a reduction below $1 \%$ in the number of vertexes, faces and the mesh surface in Rhino when comparing the resulting meshes with those obtained through Artec software. Notwithstanding, a larger number of cases could provide a more accurate percentage.

- Although the decrease in number of vertexes and faces in the STL file format seems to conclude that it is slightly less reliable in relation to geometry preservation, the extensive usage of STL and its compatibility among different software may lead to 
consider this format rather than others in some cases. However in this research, not only was PLY file format used because of its invariable geometry, but also due to the reduced file size PLY entails against STL format. This fact is extremely important in processing time and memory usage while performing operations.

- PLY, OBJ, FBX, 3DM, and 3DS file formats maintain the same features in meshes.

- It can be noticed that the number of faces approximately doubles the number of vertexes in all cases.

- Additionally, the area of the meshes remains constant using each application (Artec and Rhino, respectively), regardless the file format considered.

- $\sigma$ of STL format is slightly lower when meshing using Rhino, since the meshes differ; i.e., more vertexes in the compared mesh move from their equivalent vertexes in the reference mesh when using this software.

On the other hand, the geometrical complexity of the stone surface may be determinant in the significant difference between the test conducted on its meshes and those from the column capital, which shows a more regular geometry. The similarity between the meshes of the column capital is clearly higher than those in the case of the portion of stone surface. The reason for this is that values for $\sigma$ increase in the capital, which in turn means that there are fewer points at distances above and below the value zero.

After analysing the results of the comparative study, and considering the scarce difference in geometry preservation between these applications (Artec and Rhino) for building components (below 1\%), it could be stated that both are suitable software to be used to develop the proposal of this paper.

For its part, processing time should be also discussed. Since manual tasks such as point cloud subdivision, brushing (if necessary), file conversion and implementation in BIM depend 
on the user's skills, it is worth showing the time consumed to perform automatic processes on a large sample point cloud:

- Meshing: with 1341953 vertexes and 2683629 polygons, MeshFlow Rhino plug-in needed 4 minutes and 5 seconds to complete the meshing process from the original point cloud.

- Filling missing data: Artec filled 28 gaps in 5 seconds, creating 780 and 1,869 new vertexes and polygons, respectively.

- Simplification: 6 minutes and 22 seconds was the time Artec needed to significantly simplify the watertight mesh with $1,342,733$ vertexes and $2,685,498$ polygons to obtain a new mesh with 99,984 points and 200,000 faces.

- NURBS conversion: the process to convert that simplified closed mesh into closed polysurfaces with Rhino lasted 12 seconds.

The duration of these automatic tasks depends on the 3D mesh multiple factors (i.e. file size, and original and preferred number of points and vertexes) and hardware. The system used for this research was an average portable computer with the following main specifications: 4core microprocessor at $3.3 \mathrm{GHz}$ maximum; $16 \mathrm{~GB}$ DDRIII RAM memory at 1,600 MHz; and a PCI Express 2.0 graphic card with 336 GPU cores, 598 MHz graphics clock, and 3 GB 192bit GDDR5 memory at 1,500 MHz with bandwidth of $72 \mathrm{~GB}$ per second. Therefore, it can be stated that this proposal does not need powerful hardware to be carried out.

Concerning the scanning process, the suitability of the equipment has to be assessed as regards accuracy and cost, depending on the requirements of the project. In addition, the process has to be perfectly planned by the technicians in charge so as to prevent lack of 3D data. The scanner must be placed in different positions to record information from the sides that would be hidden if the device only aimed the surface from one angle. In short, the survey has to achieve volumes rather than surfaces when possible. 
With this methodology, signs of collapse in walls, beam deflections, lack of verticality of columns, and other pathologies are registered within the models. As displayed in Figure 10, the north-western acanthus leaf of a Corinthian column capital of the Pavilion is damaged and therefore captured in its HBIM reconstitution model.

$<$ SET FIGURE 10>

Figure 10. Defect in column capital 5 (ID tag in HBIM: Capital_5).

Although the level of detail - original or simplified according to the needs of the project - has to be taken into consideration, the singularities of a historical building and its uniqueness can be registered and referenced in the HBIM model.

This research outlines a procedure applied to architectural heritage. Nevertheless, the 3D reconstruction can also meet the aims of archaeological enquiries, as proved with the sample meshes of the stone surface analysed. Certainly, 3D surveys will not produce closed volumes in this case, but Boolean operations can be undertaken to obtain solid models out of the point cloud data.

\section{Conclusions}

The emergence of new technologies represents great advances in order to improve the quality and management of complex 3D building information. This paper proposes a new approach to analyse the accuracy of 3D models resulting from point cloud data using existing commercial BIM tools. In this paper we have suggested a semi-automatic method that can improve the accuracy of the historical building information models of heritage assets. This improvement is driven by the quantification of the deformation of the meshes we have presented in this paper.

One of the main advantages of this research lies in the utilisation of affordable, easy-to-use commercial software packages, that are available in most of architectural offices, research 
centres and universities. This will allow professionals and researchers to apply the proposed methodology to other cases where the resources are limited or the buildings to study are conform to the current limitations in hardware. Although this research considers the subdivision of the entire point cloud of the building into easy-to-handle elements, further development in hardware and software including computation power, efficiency, processing time, and memory usage are essential in the case of larger buildings.

The proposed methodology supports the 3D modelling of singular, complex historical building components, which do not exist as standard 3D components in the libraries that BIM software use, as seen in the work by Boeykens et al. (2012).

One of the main goal of this research is the 3D reconstitution of the architectural heritage in a rigorous HBIM model. This will allow the generation of reliable models to support further building analysis through simulations (Clemente et al., 2006; Murcia-Delso et al., 2009; Barazzetti et al., 2015b; Bassier et al., 2016; Compán et al., 2017) such as the Finite Element Method (FEM) to analyse the structure of the historical building (Zienkiewicz and Taylor, 1971; Roca et al., 2010). Examples of these simulations include: collapse risk analysis due to earthquakes, structure deformation, energy transmission, or those of a different nature (Pineda and Iranzo, 2017). The HBIM achieved in this paper can be used as a reference for the restoration of the building and its components, taking into account their exact position, geometry, and physical and technical characteristics. These components can be catalogued for possible use in case of future building degradation.

Further research in this field could focus on calculating the similarity among multiple samples of architectural heritage (Moyano et al., 2017), by using the 3D solid objects created through the methodology presented in this paper. The aim would be to assign the authorship of both the design and the construction of historical building components, based on the analysis of their geometry and historical-graphical documentary sources. 
Finally, it should be mentioned that BIM platforms, in addition to managing patrimonial assets, allow their dissemination to the general public through multimedia contents such using virtual reality. It is then convenient to place these tools at the service of society, highlighting the importance of their application for the preservation of our architectural heritage.

\section{Acknowledgements}

This work has been funded by the V Plan Propio de Investigación (VPPI) (Ref.: CONV-822 and PP2016-5908) of the Universidad de Sevilla, Spain. Special thanks to The Creative and Virtual Technologies Research Laboratory (Nottingham Trent University) for providing access to their facilities during the research stay. The authors also wish to acknowledge José Antonio Barrera and Enrique Nieto for collaboration in laser scanning.

\section{References}

Altuntas, C. 2015. "Integration of Point Clouds Originated from Laser Scanner and Photogrammetric Images for Visualization of Complex Details of Historical Buildings." International Archives of the Photogrammetry, Remote Sensing and Spatial Information Sciences - ISPRS Archives XL-5/W4: 431-35. doi:10.5194/isprsarchives-XL-5-W4-4312015.

Altuntas, C., F. Yildiz, and M. Scaioni. 2016. "Laser Scanning and Data Integration for ThreeDimensional Digital Recording of Complex Historical Structures: The Case of Mevlana Museum." ISPRS International Journal of Geo-Information 5 (2). Multidisciplinary Digital Publishing Institute: 18. doi:10.3390/ijgi5020018.

Armesto-González, J., B. Riveiro-Rodríguez, D. González-Aguilera, and M. T. Rivas-Brea. 2010. "Terrestrial Laser Scanning Intensity Data Applied to Damage Detection for 
Historical Buildings." Journal of Archaeological Science 37 (12). Elsevier Ltd: 3037-47. doi:10.1016/j.jas.2010.06.031.

Artec 3D. 2015. "Artec Studio Professional." https://www.artec3d.com/.

Autodesk. 2014. "AutoCAD Architecture." https://knowledge.autodesk.com/support/autocadarchitecture/downloads/caas/downloads/content/autocad-architecture-2015-servicepack-2.html.

Baik, A. 2017. "From Point Cloud to Jeddah Heritage BIM Nasif Historical House - Case Study." Digital Applications in Archaeology and Cultural Heritage 4. Elsevier: 1-18. doi:10.1016/j.daach.2017.02.001.

Baik, A., A. Alitany, J. Boehm, and S. Robson. 2014. "Jeddah Historical Building Information Modelling 'JHBIM' - Object Library.” ISPRS Annals of the Photogrammetry, Remote Sensing and Spatial Information Sciences II-5: 41-47. doi:10.5194/isprsannals-II-5-412014.

Barazzetti, L., F. Banfi, R. Brumana, D. Oreni, M. Previtali, and F. Roncoroni. 2015a. "HBIM and Augmented Information: Towards a Wider User Community of Image and RangeBased Reconstructions." International Archives of the Photogrammetry, Remote Sensing and Spatial Information Sciences - ISPRS Archives XL-5/W7: 35-42. doi:10.5194/isprsarchives-XL-5-W7-35-2015.

Barazzetti, L., F. Banfi, R. Brumana, G. Gusmeroli, M. Previtali, and G. Schiantarelli. 2015b. "Cloud-to-BIM-to-FEM: Structural Simulation with Accurate Historic BIM from Laser Scans." Simulation Modelling Practice and Theory 57. Elsevier B.V.: 71-87. doi:10.1016/j.simpat.2015.06.004.

Barber, D. M., Ross W. A. Dallas, and J. P. Mills. 2006. "Laser Scanning for Architectural Conservation." Journal of Architectural Conservation 12 (1). Routledge: 35-52. doi:10.1080/13556207.2006.10784959. 
Bassier, M., G. Hadjidemetriou, M. Vergauwen, N. Van Roy, and E. Verstrynge. 2016. "Implementation of Scan-to-BIM and FEM for the Documentation and Analysis of Heritage Timber Roof Structures." In Digital Heritage. Progress in Cultural Heritage: Documentation, Preservation, and Protection: 6th International Conference, EuroMed 2016, ed. M. loannides, E. Fink, A. Moropoulou, M. Hagedorn-Saupe, A. Fresa, G. LiestøI, V. Rajcic, and P. Grussenmeyer, 79-90. Nicosia, Cyprus: Springer International Publishing. doi:10.1007/978-3-319-48496-9_7.

Boeykens, S., C. Himpe, and B. Martens. 2012. "A Case Study of Using BIM in Historical Reconstruction. The Vinohrady Synagogue in Prague." In Proceedings of 30th eCAADe Conference, ed. H. Achten, J. Pavliček, J. Hulín, and D. Matějovská, 729-38. Prague: eCAADe (Education and research in Computer Aided Architectural Design in Europe) and CVUT, Faculty of Architecture. https://lirias.kuleuven.be/handle/123456789/350340.

Brumana, R., D. Oreni, B. Cuca, L. Binda, P. Condoleo, and M. Triggiani. 2014. "Strategy for Integrated Surveying Techniques Finalized to Interpretive Models in a Byzantine Church, Mesopotam, Albania." International Journal of Architectural Heritage 8 (6): 886924. doi:10.1080/15583058.2012.756077.

buildingSMART International. 2017. "Industry Foundation Classes (IFC)." http://www.buildingsmart-tech.org/.

Chellini, G., L. Nardini, B. Pucci, W. Salvatore, and R. Tognaccini. 2014. "Evaluation of Seismic Vulnerability of Santa Maria Del Mar in Barcelona by an Integrated Approach Based on Terrestrial Laser Scanner and Finite Element Modeling." International Journal of Architectural Heritage 8 (6). Taylor \& Francis: 795-819.

doi:10.1080/15583058.2012.747115.

Chiabrando, F., G. Sammartano, and A. Spanò. 2016. "Historical Buildings Models and Their Handling via 3d Survey: From Points Clouds to User-Oriented HBIM.” International Archives of the Photogrammetry, Remote Sensing and Spatial Information Sciences - 
ISPRS Archives XLI-B5: 633-40. doi:10.5194/isprsarchives-XLI-B5-633-2016.

Cignoni, P., M. Callieri, M. Corsini, M. Dellepiane, F. Ganovelli, and G. Ranzuglia. 2008.

"MeshLab: an Open-Source Mesh Processing Tool" In Proceedings of Sixth

Eurographics Italian Chapter Conference, ed. V. Scarano, R. De Chiara, and U. Erra, 129-136. Salerno, Italy: The Eurographics Association.

doi:10.2312/LocalChapterEvents/ItalChap/ItalianChapConf2008/129-136

Clemente, R., P. Roca, and M. Cervera. 2006. "Damage Model with Crack Localization Application to Historical Buildings." In 5th International Conference on Structural Analysis of Historical Constructions, ed. P. B. Lourenço, P. Roca, C. Modena, and S. Agrawal, 1125-33. New Delhi: MacMillan India Ltd. http://www.hms.civil.uminho.pt/sahc/2006/1125.pdf.

Compán, V., P. Pachón, M. Cámara, P. B. Lourenço, and A. Sáez. 2017. "Structural Safety Assessment of Geometrically Complex Masonry Vaults by Non-Linear Analysis . The Chapel of the Würzburg Residence (Germany)." Engineering Structures 140: 1-13. doi:https://doi.org/10.1016/j.engstruct.2017.03.002.

Dassault Systèmes, and SolidWorks Corporation. 2017. "SolidWorks: 3D CAD Design Software." http://www.solidworks.com/.

Dore, C., and M. Murphy. 2013. "Semi-Automatic Modelling of Building Façades with Shape Grammars Using Historic Building Information Modelling." International Archives of the Photogrammetry, Remote Sensing and Spatial Information Sciences - ISPRS Archives XL-5/W1: 57-64. doi:10.5194/isprsarchives-XL-5-W1-57-2013.

Dore, C., M. Murphy, S. McCarthy, F. Brechin, C. Casidy, and E. Dirix. 2015. "Structural Simulations and Conservation Analysis-Historic Building Information Model (HBIM)." International Archives of the Photogrammetry, Remote Sensing and Spatial Information Sciences - ISPRS Archives XL-5/W4: 351-57. doi:10.5194/isprsarchives-XL-5-W4-3512015. 
Dore, C., and M. Murphy. 2017. "Current State of the Art Historic Building Information Modelling." ISPRS - International Archives of the Photogrammetry, Remote Sensing and Spatial Information Sciences XLII-2/W5 (September): 185-92. doi:10.5194/isprsarchives-XLII-2-W5-185-2017.

El-Hakim, S. F., J. A. Beraldin, M. Picard, and G. Godin. 2004. "Detailed 3D Reconstruction of Large-Scale Heritage Sites with Integrated Techniques." IEEE Computer Graphics and Applications 24 (3): 21-29. doi:10.1109/MCG.2004.1318815.

Fai, S., K. Graham, T. Duckworth, N. Wood, and R. Attar. 2011. "Building Information Modelling and Heritage Documentation." In Proceedings of XXIIIrd International CIPA Symposium, ed. K. Pavelka. Prague: Czech Technical University in Prague, Faculty of Civil Engineering, and CIPA.

https://pdfs.semanticscholar.org/b76a/6be1ab4c5c148757eac8c73dc7a5c2995999.pdf.

Fregonese, L., L. Taffurelli, A. Adami, S. Chiarini, S. Cremonesi, J. Helder, and A. Spezzoni. 2017. "Survey and Modelling for the Bim of Basilica of San Marco in Venice." International Archives of the Photogrammetry, Remote Sensing and Spatial Information Sciences - ISPRS Archives XLII-2/W3: 303-10. doi:10.5194/isprs-archives-XLII-2-W3303-2017.

Girardeau-Montaut, D. 2015. "Cloud-to-Mesh Distance." http://www.cloudcompare.org/doc/wiki/index.php?title=Cloud-to-Mesh_Distance.

Girardeau-Montaut, D. 2016. "CloudCompare: 3D Point Cloud and Mesh Processing Software. Open Source Project." http://www.danielgm.net/cc/.

Graphisoft. 2016. "ArchiCAD.” http://www.graphisoft.com/archicad/.

Guarnieri, A., N. Milan, and A. Vettore. 2013. "Monitoring Of Complex Structure For Structural Control Using Terrestrial Laser Scanning (TLS) And Photogrammetry." International Journal of Architectural Heritage 7 (1). Taylor \& Francis: 54-67. 
doi:10.1080/15583058.2011.606595.

Hajian, H., and B. Becerik-Gerber. 2010. "Scan to BIM: Factors Affecting Operational and Computational Errors and Productivity Loss." In 27th International Symposium on Automation and Robotics in Construction (ISARC), ed. J. Gašparík, 265-72. Bratislava, Slovakia: International Association of Automation and Robotics in Construction. http://www.iaarc.org/publications/fulltext/Scan_to_BIM_factors_affecting_operational_an d_computational_errors_and_productivity_loss.pdf.

Hichri, N., C. Stefani, L. De Luca, and P. Veron. 2013. "Review of the « As-Built Bim» Approaches." International Archives of the Photogrammetry, Remote Sensing and Spatial Information Sciences - ISPRS Archives XL-5/W1: 107-12. doi:10.5194/isprsarchives-XL-5-W1-107-2013.

Hong, S., J. Jung, S. Kim, H. Cho, J. Lee, and J. Heo. 2015. "Semi-Automated Approach to Indoor Mapping for 3D as-Built Building Information Modeling." Computers, Environment and Urban Systems 51 (May). Elsevier Ltd: 34-46.

doi:10.1016/j.compenvurbsys.2015.01.005.

Huber, D., B. Akinci, A. Stambler, X. Xiong, E. Anil, and A. Adan. 2011. "Methods for Automatically Modeling and Representing as-Built Building Information Models." In Proceedings of the NSF CMMI Research Innovation Conference. Atlanta, Georgia. https://www.ri.cmu.edu/pub_files/2011/1/2011-huber-cmmi-nsf-v4.pdf.

International Organization for Standardization (ISO). 2013. ISO 16739:2013-Industry Foundation Classes (IFC) for Data Sharing in the Construction and Facility Management Industries. https://www.iso.org/standard/51622.html.

Jung, J., S. Hong, S. Jeong, S. Kim, H. Cho, S. Hong, and J. Heo. 2014. "Productive Modeling for Development of as-Built BIM of Existing Indoor Structures." Automation in Construction 42 (June). Elsevier B.V.: 68-77. doi:10.1016/j.autcon.2014.02.021. 
Kazhdan, M., and H. Hoppe. 2013. "Screened Poisson Surface Reconstruction”. ACM Transactions on Graphics 32 (3). doi: http://dx.doi.org/10.1145/2487228.2487237

Kim, M., H. Sohn, C.-C. Chang. 2015. "Localization and Quantification of Concrete Spalling Defects Using Terrestrial Laser Scanning." Journal of Computing in Civil Engineering 29 (6). American Society of Civil Engineers. doi:10.1061/(ASCE)CP.1943-5487.0000415.

Leica Geosystems. 2016a. “Leica Cyclone.” http://hds.leica-geosystems.com/en/leicacyclone_6515.htm.

Leica Geosystems. 2016b. "Leica ScanStation C10 - The All-in-One Laser Scanner for Any Application." http://leica-geosystems.com/products/laser-scanners/scanners/leicascanstation-c10.

Lezzerini, M., F. Antonelli, S. Columbu, R. Gadducci, A. Marradi, D. Miriello, L. Parodi, L. Secchiari, and A. Lazzeri. 2016. "Cultural Heritage Documentation and Conservation: Three-Dimensional (3D) Laser Scanning and Geographical Information System (GIS) Techniques for Thematic Mapping of Facade Stonework of St. Nicholas Church (Pisa, Italy)." International Journal of Architectural Heritage 10 (1). Taylor \& Francis: 9-19. doi:10.1080/15583058.2014.924605.

Logothetis, S., A. Delinasiou, and E. Stylianidis. 2015. "Building Information Modelling for Cultural Heritage: A Review." ISPRS Annals of Photogrammetry, Remote Sensing and Spatial Information Sciences II-5/W3: 177-83. doi:10.5194/isprsannals-II-5-W3-1772015.

Logothetis, S., and E. Stylianidis. 2016. "Bim Open Source Software (Oss) for the Documentation of Cultural Heritage." Virtual Archaeology Review 7 (15): 28-35. doi:http://dx.doi.org/10.4995/var.2016.5864.

Mesh Reverse. 2016. "Mesh Flow." http://www.meshreverse.com/download.html.

Mill, T., A. Alt, and R. Liias. 2013. "Combined 3D Building Surveying Techniques - Terrestrial 
Laser Scanning (TLS) and Total Station Surveying for BIM Data Management Purposes." Journal of Civil Engineering and Management 19 (sup1). Taylor \& Francis: S23-32. doi:10.3846/13923730.2013.795187.

Moyano, J. J., J. A. Barrera, J. E. Nieto, D. Marín, and D. Antón. 2017. “A Geometrical Similarity Pattern as an Experimental Model for Shapes in Architectural Heritage: a Case Study of the Base of the Pillars in the Cathedral of Seville and the Church of Santiago in Jerez, Spain." International Archives of the Photogrammetry, Remote Sensing and Spatial Information Sciences - ISPRS Archives XLII-2/W3: 511-17. doi:10.5194/isprs-archives-XLII-2-W3-511-2017.

Mukupa, W., G. W. Roberts, C. M. Hancock, and K. Al-Manasir. 2016. "A Review of the Use of Terrestrial Laser Scanning Application for Change Detection and Deformation Monitoring of Structures." Survey Review. Taylor \& Francis: 1-18. doi:10.1080/00396265.2015.1133039.

Murcia-Delso, J., A. Kumar Das, P. Roca, and M. Cervera. 2009. "Seismic Safety Analysis of Historical Masonry Structures Using a Damage Constitutive Model." In COMPDYN 2009. ECCOMAS 2nd International Conference on Computational Methods in Structural Dynamics and Earthquake Engineering, edited by M. Papadrakakis, N.D. Lagaros, and M. Fragiadakis. Rhodes, Greece: Institute of Structural Analysis \& Seismic Research, National Technical University of Athens. http://www.eccomas.org/vpage/1/14/2009.

Murphy, M., E. McGovern, and S. Pavia. 2009. "Historic Building Information Modelling (HBIM)." Structural Survey 27 (4). Emerald: 311-27. doi:10.1108/02630800910985108.

Murphy, M., E. McGovern, and S. Pavia. 2013. "Historic Building Information Modelling Adding Intelligence to Laser and Image Based Surveys of European Classical Architecture." ISPRS Journal of Photogrammetry and Remote Sensing 76: 89-102. doi:10.1016/j.isprsjprs.2012.11.006.

Nabil, M., and F. Saleh. 2014. "3D Reconstruction from Images for Museum Artefacts: A 
Comparative Study." In 2014 International Conference on Virtual Systems \& Multimedia (VSMM), 257-60. IEEE. doi:10.1109/VSMM.2014.7136681.

Nieto, J. E., J. J. Moyano, and P. Fernández-Valderrama. 2014. "Implementación de Las Nuevas Técnicas de Levantamiento En El Sistema BIM (Building Information Modeling)." In XII Graphic Expression Applied to Building International Conference (APEGA 2014), ed. Universidad Europea de Madrid, 104-13. Madrid: Editorial Rueda, S.L.

Nieto, J. E., J. J. Moyano, F. Rico, and D. Antón. 2016. "Management of Built Heritage via the HBIM Project: A Case of Study of Flooring and Wall Tiling." Virtual Archaeology Review 7 (14): 1-12. doi:10.4995/var.2016.4349.

Olsen, M., F. Kuester, B. Chang, and T. Hutchinson. 2009. “Terrestrial Laser ScanningBased Structural Damage Assessment." Journal of Computing in Civil Engineering 24 (3). American Society of Civil Engineers: 264-72. doi:10.1061/(ASCE)CP.19435487.0000028.

Oreni, D. 2013. "From 3D Content Models to HBIM for Conservation and Management of Built Heritage." In Computational Science and Its Applications-ICCSA. Edited by B. Murgante, S. Misra, M. Carlini, C. M. Torre, H.-Q. Nguyen, D. Taniar, B. O. Apduhan, and O. Gervasi. 344-357. Ho Chi Minh City, Vietnam: Springer Berlin Heidelberg doi:10.1007/978-3-642-39649-6_25.

Oreni, D., R. Brumana, S. Della Torre, F. Banfi, L. Barazzetti, and M. Previtali. 2014. "Survey Turned into HBIM: The Restoration and the Work Involved Concerning the Basilica Di Collemaggio after the Earthquake (L'Aquila)." ISPRS Annals of Photogrammetry, Remote Sensing and Spatial Information Sciences II-5: 267-73. doi:10.5194/isprsannals-II-5-267-2014.

Pesci, A., G. Teza, E. Bonali, G. Casula, and E. Boschi. 2013. "ISPRS Journal of Photogrammetry and Remote Sensing A Laser Scanning-Based Method for Fast 
Estimation of Seismic-Induced Building Deformations." ISPRS Journal of Photogrammetry and Remote Sensing 79. International Society for Photogrammetry and Remote Sensing, Inc. (ISPRS): 185-98. doi:10.1016/j.isprsjprs.2013.02.021.

Pineda, P., and A. Iranzo. 2017. "ScienceDirect Analysis of Sand-Loaded Air Flow Erosion in Heritage Sites by Computational Fluid Dynamics : Method and Damage Prediction." Journal of Cultural Heritage 25. Elsevier Masson SAS: 75-86. doi:10.1016/j.culher.2016.12.005.

Previtali, M., L. Barazzetti, R. Brumana, and M. Scaioni. 2014. "Scan Registration Using Planar Features." ISPRS - International Archives of the Photogrammetry, Remote Sensing and Spatial Information Sciences XL-5 (June): 501-8. doi:10.5194/isprsarchives-XL-5-501-2014.

Pu, S., and G. Vosselman. 2009. "Knowledge Based Reconstruction of Building Models from Terrestrial Laser Scanning Data." ISPRS Journal of Photogrammetry and Remote Sensing 64 (6). Elsevier B.V.: 575-84. doi:10.1016/j.isprsjprs.2009.04.001.

Remondino, F., and A. Rizzi. 2010. "Reality-Based 3D Documentation of Natural and Cultural Heritage Sites-Techniques, Problems, and Examples." Applied Geomatics 2 (3): 85100. doi:10.1007/s12518-010-0025-x.

Robert McNeel \& Associates. 2014. "Rhinoceros." https://www.rhino3d.com/.

Robert McNeel \& Associates. 2015. "UnifyMeshNormals." http://docs.mcneel.com/rhino/5/help/en-us/commands/unifymeshnormals.htm.

Roca, P., M. Cervera, G. Gariup, and L. Pelà. 2010. "Structural Analysis of Masonry Historical Constructions . Classical and Advanced Approaches." Archives of Computational Methods in Engineering 17 (3): 299-325. doi:10.1007/s11831-010-90461.

Saygi, G., and F. Remondino. 2013. "Management of Architectural Heritage Information in 
BIM and GIS: State-of-the-Art and Future Perspectives." International Journal of Heritage in the Digital Era 2 (4): 695-714. doi:10.1260/2047-4970.2.4.695.

Simeone, D., S. Cursi, I. Toldo, and G. Carrara. 2014. "B(H)IM - Built Heritage Information Modelling - Extending BIM Approach to Historical and Archaeological Heritage Representation." In Fusion, Proceedings of the 32nd International Conference on Education and Research in Computer Aided Architectural Design in Europe, eCAADe Conferences, 1:613-22. Newcastle upon Tyne.

https://cumincad.architexturez.net/doc/oai-cumincadworks-id-ecaade2014-204.

Tang, P., D. Huber, B. Akinci, R. Lipman, and A. Lytle. 2010. "Automatic Reconstruction of as-Built Building Information Models from Laser-Scanned Point Clouds: A Review of Related Techniques." Automation in Construction 19 (7). Elsevier B.V.: 829-43. doi:10.1016/j.autcon.2010.06.007.

Thomson, C., and J. Boehm. 2015. "Automatic Geometry Generation from Point Clouds for BIM." Remote Sensing 7 (9): 11753-75. doi:10.3390/rs70911753.

United Nations Educational, Scientific and Cultural Organization (UNESCO). 1987. "Cathedral, Alcázar and Archivo de Indias in Seville." http://whc.unesco.org/es/list/383\#top.

Unity Technologies. 2016. "Unity Manual." https://docs.unity3d.com/es/current/Manual/AnatomyofaMesh.html.

Volk, R., J. Stengel, and F. Schultmann. 2014. "Building Information Modeling (BIM) for Existing Buildings - Literature Review and Future Needs." Automation in Construction 38. Elsevier B.V.: 109-27. doi:10.1016/j.autcon.2013.10.023.

Xiong, X., A. Adan, B. Akinci, and D. Huber. 2013. "Automatic Creation of Semantically Rich 3D Building Models from Laser Scanner Data." Automation in Construction 31. Elsevier B.V.: 325-37. doi:10.1016/j.autcon.2012.10.006. 
Zeibak-Shini, R., R. Sacks, and S. Filin. 2012. "Toward Generation of a Building Information Model of a Deformed Structure Using Laser Scanning Technology." In 14th International Conference on Computing in Civil and Building Engineering (ICCCBE). Moscow, Russia: International Society for Computing in Civil and Building Engineering.

Zhang, R., and A. Zakhor. 2014. "Automatic Identification of Window Regions on Indoor Point Clouds Using LiDAR and Cameras." In IEEE Winter Conference on Applications of Computer Vision, ed. T. Boult, F. Porikli, and S. Belongie, 107-14. Steamboat Springs, Colorado, United States: IEEE. doi:10.1109/WACV.2014.6836112.

Zienkiewicz, O. C., and R. L. Taylor. 2000. The Finite Element Method Volume 1: The Basis. 5thed. Vol. 1. Butterworth-Heinemann. 


\section{Figure captions (as a list)}

Figure 1. TLS and OS accuracy difference in a column capital.

Figure 2. Flowchart explaining the 'Point cloud - mesh - 3D solid object' process.

Figure 3. Results from different meshing plug-ins in wireframe display mode.

Figure 4. Sample of irregular stone surface.

Figure 5. Stone surface: mesh deviation comparison graph.

Figure 6. Comparison histogram: deviation between Artec PLY and Rhino PLY meshes.

Figure 7. Capital: mesh deviation comparison graph.

Figure 8. Historical Building Information Model (HBIM) of the Pavilion of Charles V. Source: (Nieto et al., 2016).

Figure 9. 3D reconstitution and HBIM: arches and columns in the Pavilion of Charles V.

Figure 10. Defect in column capital 5 (ID tag in HBIM: Capital_5). 
3D modelling accuracy evaluation for HBIM

\section{Table captions (as a list)}

Table 1. Mesh feature comparison between different meshing plug-ins.

Table 2. File formats and mesh feature comparison in the case of the stone surface.

Table 3. File formats and mesh feature comparison in the case of the column capital. 
Figures with captions (individual sheets)

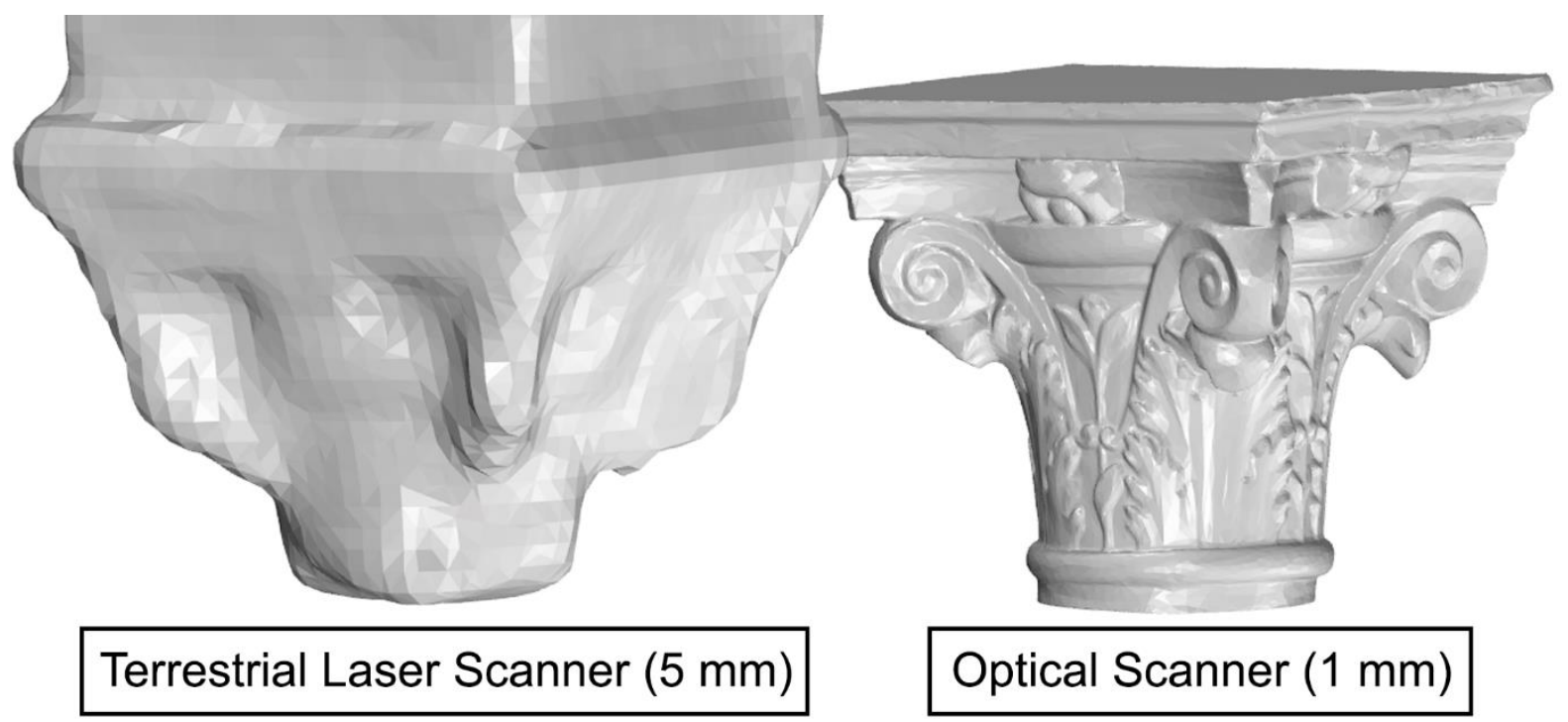

Figure 1. TLS and OS accuracy difference in a column capital. 


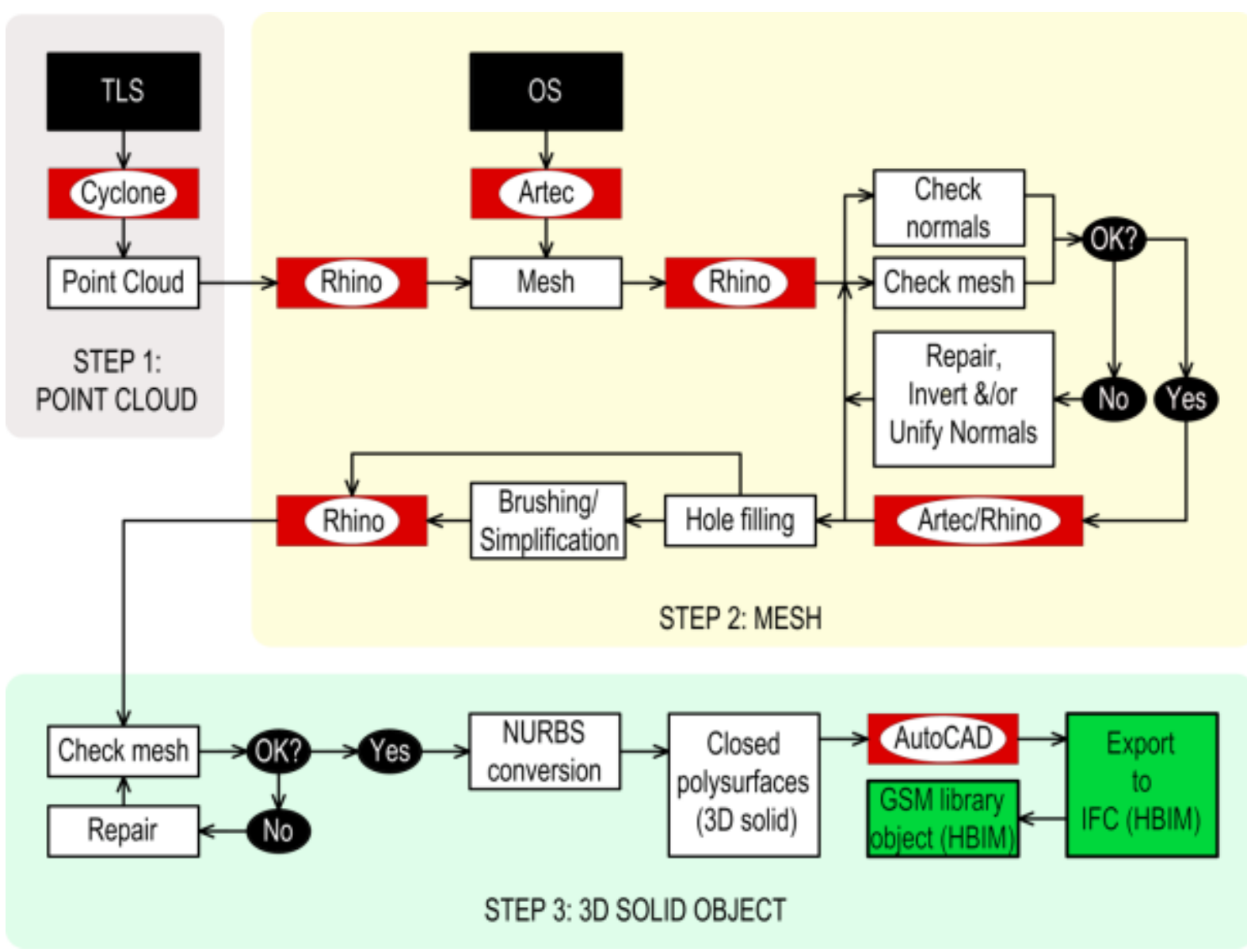

Figure 2. Flowchart explaining the 'Point cloud — mesh - 3D solid object' process. 


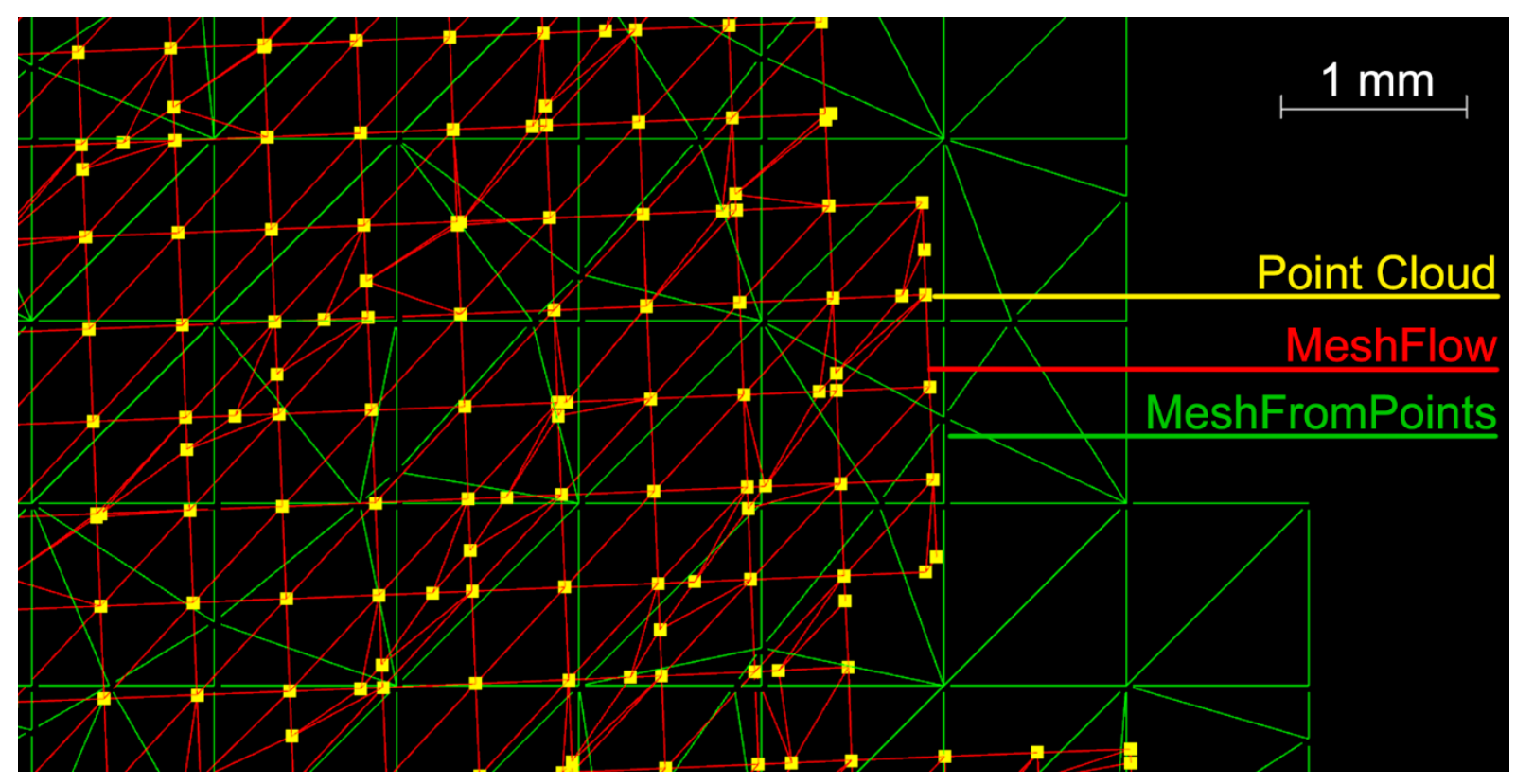

Figure 3. Results from different meshing plug-ins in wireframe display mode. 


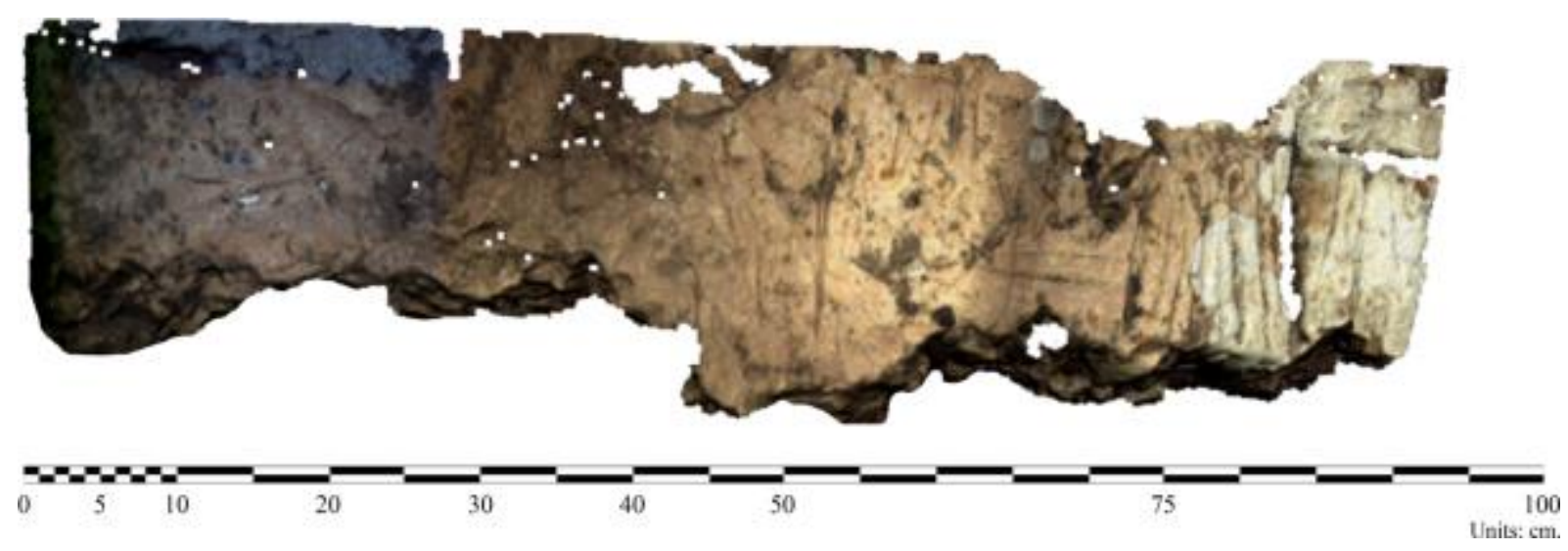

Figure 4. Sample of irregular stone surface. 


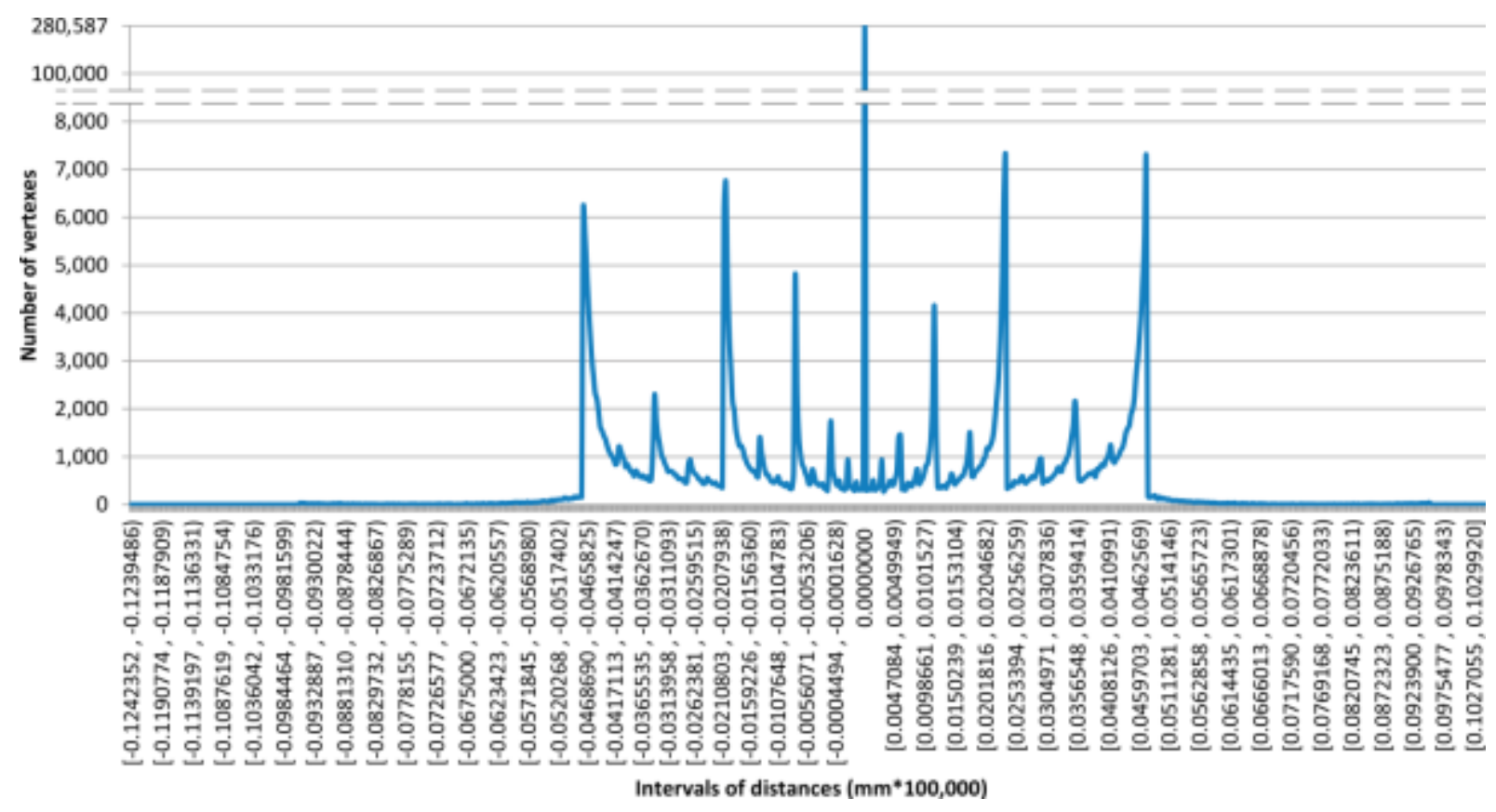

Figure 5. Stone surface: mesh deviation comparison graph. 


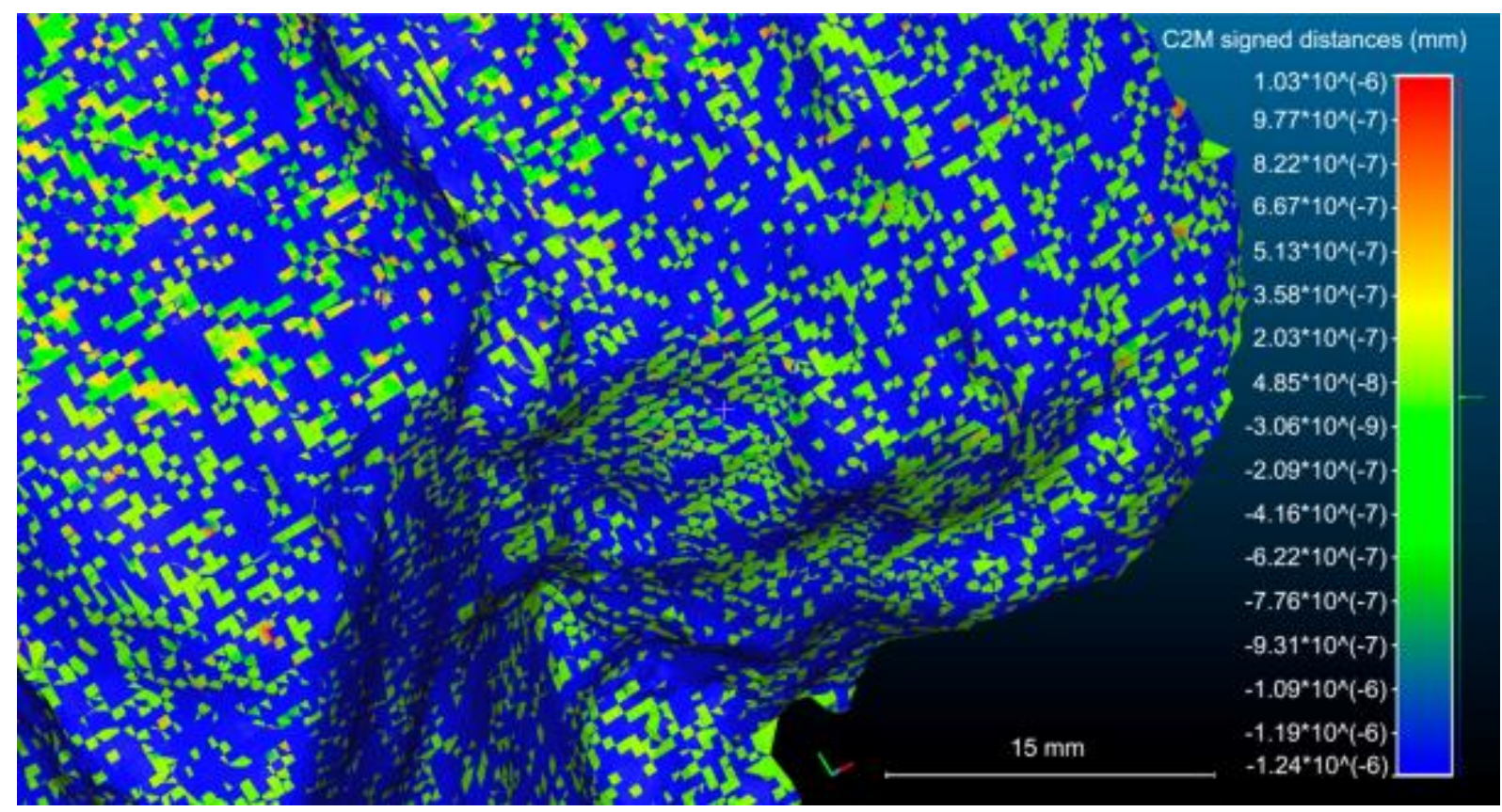

Figure 6. Comparison histogram: deviation between Artec PLY and Rhino PLY meshes. 


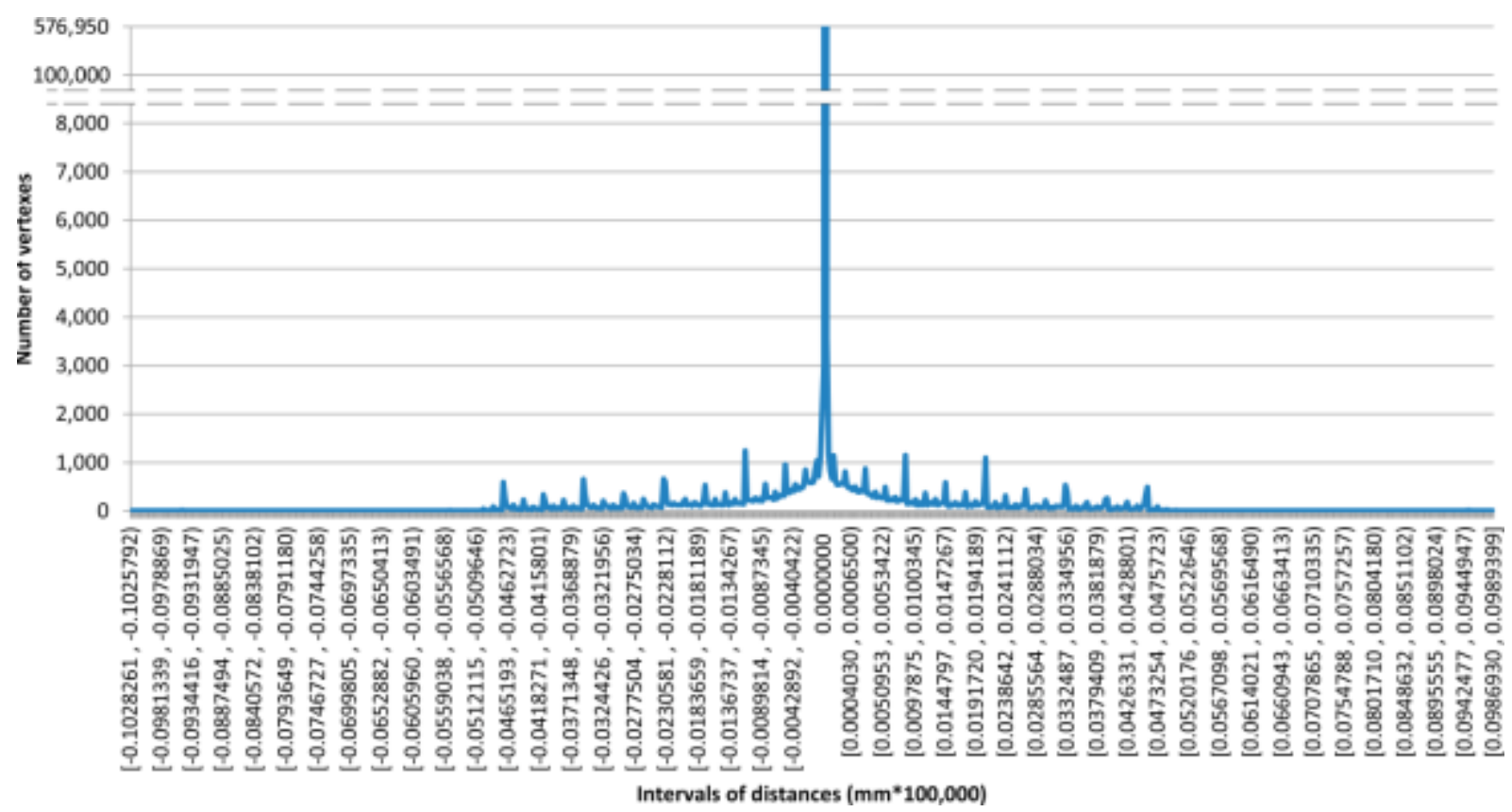

Figure 7. Capital: mesh deviation comparison graph. 


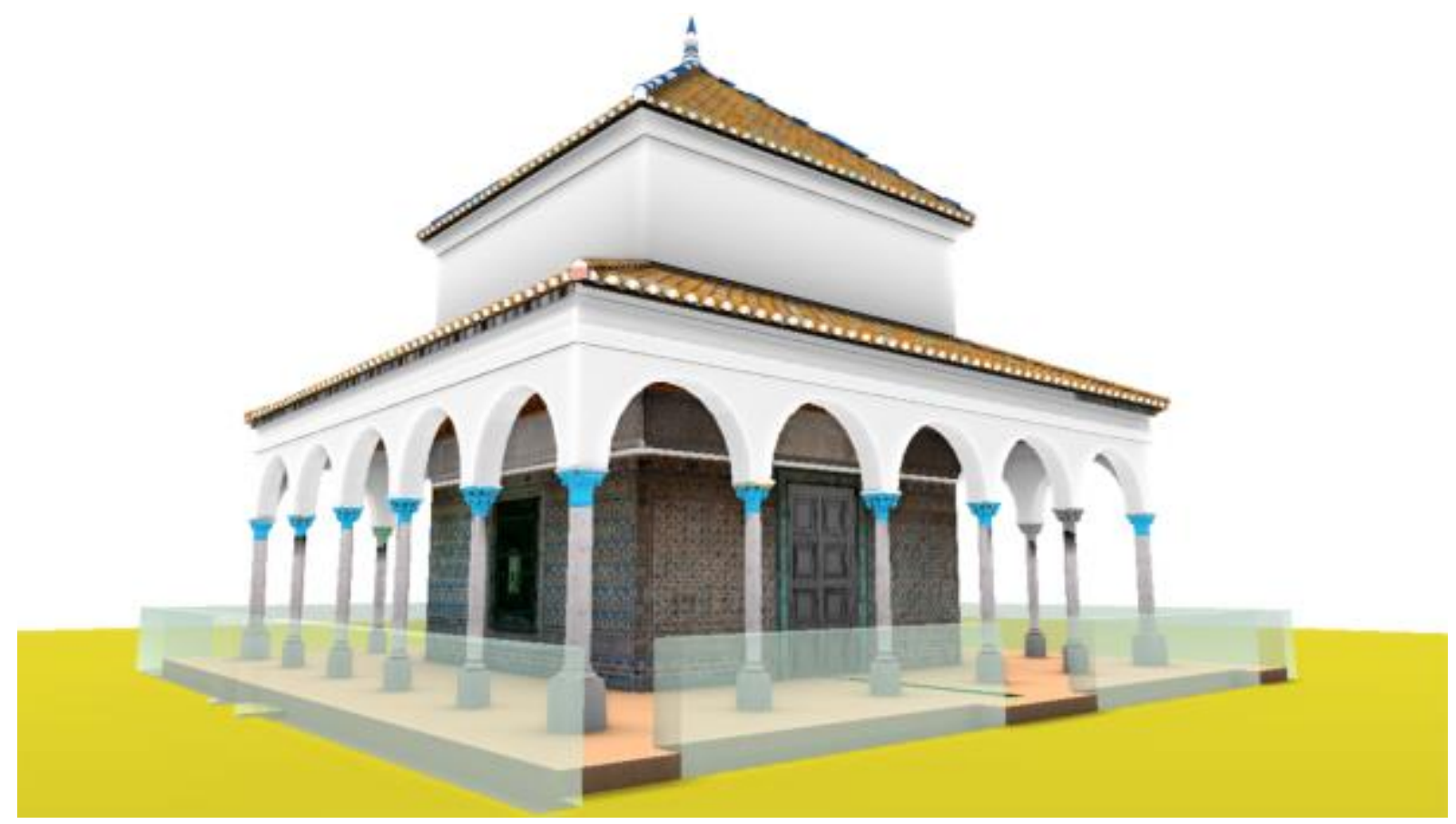

Figure 8. Historical Building Information Model (HBIM) of the Pavilion of Charles V. Source: (Nieto et al., 2016). 


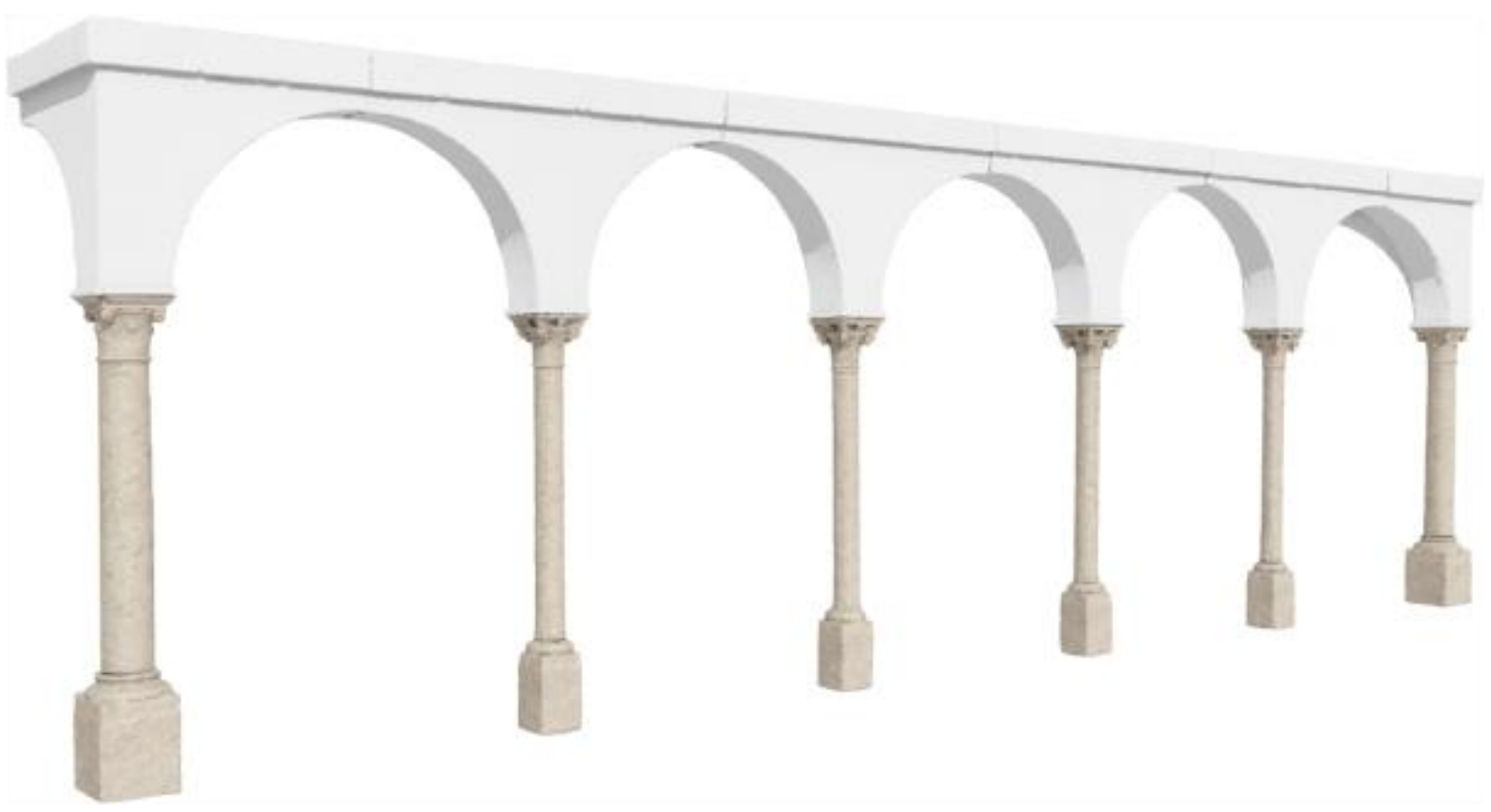

Figure 9. 3D reconstitution and HBIM. Arches and columns in the Pavilion of Charles V. 


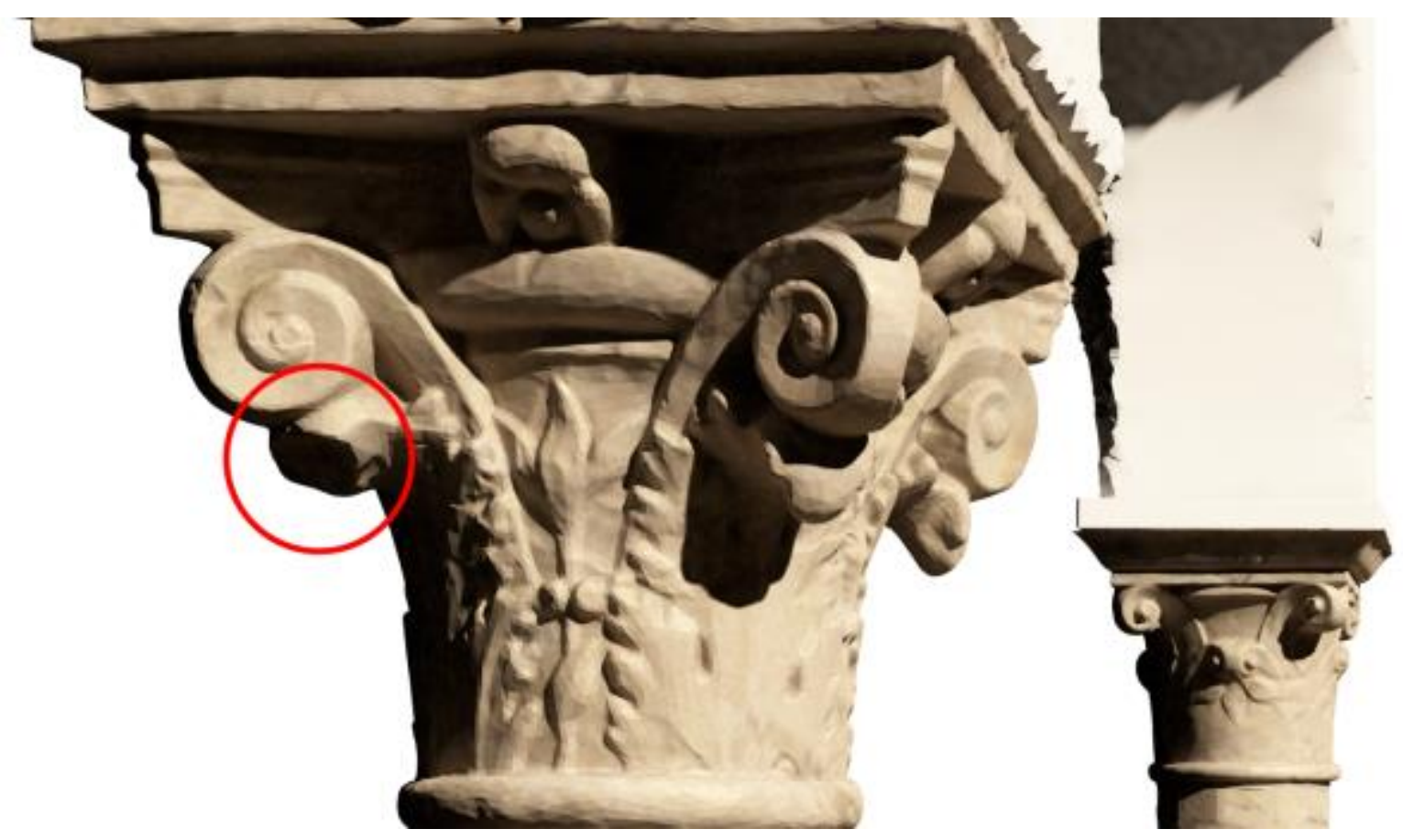

Figure 10. Defect in column capital 5 (ID tag in HBIM: Capital_5). 
3D modelling accuracy evaluation for HBIM

\section{Tables with captions (individual sheets)}

\begin{tabular}{|c|c|c|c|c|c|}
\hline $\begin{array}{c}\text { Software } \\
\text { and file } \\
\text { format }\end{array}$ & vertexes & faces & $\begin{array}{c}\text { Mesh } \\
\text { surface } \\
\left(\mathbf{m m}^{2}\right)\end{array}$ & $\begin{array}{c}\text { Mesh surface } \\
\text { per triangle } \\
\text { (average) }\left(\mathbf{m m}^{2}\right)\end{array}$ & $\begin{array}{c}\text { Standard } \\
\text { deviation }(\boldsymbol{\sigma})\end{array}$ \\
\hline 1 PLY & $2,593,806$ & $1,296,903$ & 119,598 & 0.0922182 & $0^{*}$ \\
\hline 2 PLY & 174,519 & 343,911 & 121,791 & 0.3541350 & 1183.550375 \\
\hline
\end{tabular}

*This value accounts for the equality between the meshes compared.

Table 1. Mesh feature comparison between different meshing plug-ins. 


\begin{tabular}{|c|c|c|c|c|c|}
\hline $\begin{array}{c}\text { Software } \\
\text { and file } \\
\text { format }\end{array}$ & vertexes & faces & $\begin{array}{c}\text { Mesh } \\
\text { surface } \\
\left(\mathbf{m m}^{2}\right)\end{array}$ & $\begin{array}{c}\text { Mesh surface } \\
\text { per triangle } \\
\text { (average) }\left(\mathbf{m m}^{2}\right)\end{array}$ & $\begin{array}{c}\text { Standard } \\
\text { deviation }(\boldsymbol{\sigma})\end{array}$ \\
\hline Artec PLY & 653,667 & $1,296,903$ & 119,598 & 0.0922182 & $0^{*}$ \\
\hline Artec OBJ & 653,667 & $1,296,903$ & 119,598 & 0.0922182 & 0 \\
\hline Artec FBX & 653,667 & $1,296,903$ & 119,598 & 0.0922182 & 0 * \\
\hline Artec STL & 653,487 & $1,296,544$ & 119,598 & 0.0922437 & $22,975.4068$ \\
\hline Rhino PLY & 645,900 & $1,285,697$ & 119,474 & 0.0929255 & $9,921.7959$ \\
\hline Rhino OBJ & 645,900 & $1,285,697$ & 119,474 & 0.0929255 & $9,921.7959$ \\
\hline Rhino FBX & 645,900 & $1,285,697$ & 119,474 & 0.0929255 & $9,921.7959$ \\
\hline
\end{tabular}

*This value accounts for the equality between the meshes compared.

${ }^{* *}$ Standard deviation applicable in case of Artec STL - Rhino STL.

Table 2. File formats and mesh feature comparison in the case of the stone surface. 


\begin{tabular}{|c|c|c|c|c|c|}
\hline $\begin{array}{l}\text { Software } \\
\text { and file } \\
\text { format }\end{array}$ & $\begin{array}{c}\text { Number of } \\
\text { vertexes }\end{array}$ & $\begin{array}{c}\text { Number of } \\
\text { faces }\end{array}$ & $\begin{array}{l}\text { Mesh } \\
\text { surface } \\
\left(\mathrm{mm}^{2}\right)\end{array}$ & $\begin{array}{l}\text { Mesh surface } \\
\text { per triangle } \\
\text { (average) }\left(\mathrm{mm}^{2}\right)\end{array}$ & $\begin{array}{c}\text { Standard } \\
\text { deviation }(\sigma)\end{array}$ \\
\hline Artec PLY & 668,929 & $1,337,825$ & 517,128 & 0.386544 & $0^{*}$ \\
\hline Artec OBJ & 668,929 & $1,337,825$ & 517,128 & 0.386544 & $0^{*}$ \\
\hline Artec FBX & 668,929 & $1,337,825$ & 517,128 & 0.386544 & $0^{*}$ \\
\hline Artec STL & 668,798 & $1,337,563$ & 517,128 & 0.386620 & $23,384.0031$ \\
\hline Rhino PLY & 667,110 & $1,331,274$ & 515,721 & 0.387389 & $20,182.5763$ \\
\hline Rhino OBJ & 667,110 & $1,331,274$ & 515,721 & 0.387389 & $20,182.5763$ \\
\hline Rhino FBX & 667,110 & $1,331,274$ & 515,721 & 0.387389 & $20,182.5763$ \\
\hline Rhino STL & 665,280 & $1,328,368$ & 515,721 & 0.388237 & $23,280.6608^{\star *}$ \\
\hline
\end{tabular}

* This value accounts for the equality between the meshes compared.

${ }^{* *}$ Standard deviation applicable in case Artec STL - Rhino STL.

Table 3. File formats and mesh feature comparison in the case of the column capital. 